Please do not remove this page

RMIT

UNIVERSITY

\title{
Locating and sizing energy storage systems for distribution feeder expansion planning
}

MacRae, Cameron; Ozlen, Melih; Ernst, Andreas; Behrens, Sam

https://researchrepository.rmit.edu.au/esploro/outputs/9921862274301341/filesAndLinks?institution=61RMIT_INST\&index=null

MacRae, C., Ozlen, M., Ernst, A., \& Behrens, S. (2015). Locating and sizing energy storage systems for distribution feeder expansion planning. Proceedings of the IEEE Region 10 Conference (TENCON 2015), 1-6. https://doi.org/10.1109/TENCON.2015.7373107

Document Version: Accepted Manuscript

Published Version: https://doi.org/10.1109/TENCON.2015.7373107

Repository homepage: https://researchrepository.rmit.edu.au

(C) 2015 IEEE

Downloaded On 2023/04/26 22:54:01 +1000

Please do not remove this page 
Thank you for downloading this document from the RMIT Research Repository.

The RMIT Research Repository is an open access database showcasing the research outputs of RMIT University researchers.

RMIT Research Repository: http://researchbank.rmit.edu.au/

\section{Citation:}

MacRae, C, Ozlen, M, Ernst, A and Behrens, S 2015, 'Locating and sizing energy storage systems for distribution feeder expansion planning', in Proceedings of the IEEE Region 10 Conference (TENCON 2015), United States, 1-4 November 2015, pp. 1-6.

See this record in the RMIT Research Repository at:

https://researchbank.rmit.edu.au/view/rmit:35732

Version: Accepted Manuscript

Copyright Statement: (C) 2015 IEEE

Link to Published Version:

http://dx.doi.org/10.1109/TENCON.2015.7373107 


\title{
Locating and sizing energy storage systems for distribution feeder expansion planning
}

\author{
Cameron MacRae*, Melih Ozlen*, Andreas Ernst ${ }^{\dagger}$ and Sam Behrens ${ }^{\dagger}$ \\ * School of Mathematical and Geospatial Sciences \\ RMIT University \\ GPO Box 2476, Melbourne VIC 3001, Australia \\ Email: cameron.macrae@rmit.edu.au I melih.ozlen@rmit.edu.au \\ $\dagger$ CSIRO \\ PO Box 330, Newcastle NSW 2300, Australia \\ Email: andreas.ernst@csiro.au I sam.behrens@csiro.au
}

\begin{abstract}
In this paper we present a mixed integer programming (MIP) formulation of an electricity network expansion planning model that considers the location, sizing, and operation of energy storage systems (ESS) as well as additional circuits. The model includes constraints to manage generator ramp rates, ESS charge/discharge rates, and losses on power transferred to, from, and within storage. Two new test networks based on representative feeder taxonomies identified by the National Feeder Taxonomy Study are used to demonstrate the use of the model, and a procedure to create other such test systems is defined. We find that ESS are typically omitted from the expansion plan as the cost of installing the new circuits is currently less than the cost of distribution scale energy storage.
\end{abstract}

Keywords-power transmission, energy storage, optimization

\section{INTRODUCTION}

Classical electricity network design problems, such as distribution expansion planning (DEP) and transmission expansion planning (TEP), are demanding optimization problems with the objective of producing a minimum cost expansion plan that satisfies a set of capacity, security, spatial, or environmental constraints while matching peak demand in the network.

The DEP and TEP problems have received considerable attention in the literature. A review of distribution expansion planning models is available in [1]. A set of standard models and test systems for transmission expansion planning problems are given in [2], including a worked example for the ubiquitous Garver's 6-bus system [3].

Integrating highly variable forms of renewable generation such as solar PV and wind into the grid presents a number of challenges for network planners as they can typically be predicted only in a limited way. Energy storage systems (ESS) provide a way to address these challenges through the peak cutting and smoothing supply. Hydro, while providing relatively cheap storage for large amounts of energy, is constrained both by climate and geography. Other forms of short term storage technologies such as compressed air and batteries are significantly more expensive, however the respective technologies are developing rapidly and future cost reductions are likely.
Locating and sizing storage in the distribution and transmission networks is an emerging area of research. Mixed integer programming (MIP) has been used to develop an extension to a disjunctive TEP formulation that considers the location of ESS [4], and for transmission network planning that considers both line losses and storage [5].

A load matching linear programming (LP) model is compared with a cost minimizing LP-based model for the design of a high voltage direct current (HVDC) transmission network with both variable generation and dispatchable generation as well as energy storage [6]. The load matching model installs a higher proportion of variable generation and is less computationally demanding than the cost minimizing model. Storage is installed by the load matching model, but is omitted from the cost minimizing plan due to its relatively high cost.

A range of other optimization techniques have recently been applied, including; the modified particle swarm optimization (PSO) of a multi-period distribution network design problem that considered both distributed generation and storage [7]; a genetic algorithm combined with simulated annealing to plan a low voltage distribution network with high solar PV penetration [8]; and robust optimization of storage investment in transmission networks [9].

The aforementioned research has focused on the peak cutting potential of storage, however ESS may also be deployed to ensure smoothness and stability of variable generators before presentation to the grid [10]. Approaches to sizing storage for this purpose include linear programming [11], and spectral analysis [12].

In this paper we present an improved formulation of a TEP with storage model first used for transmission expansion planning in [13]. The model addresses a number of shortcomings in the original model with the inclusion of new constraints to manage generator ramp rates, ESS charge/discharge rates, and losses on power transferred to, from and within storage. The model is tested on two specially modified representative feeder taxonomies identified by the National Feeder Taxonomy Study [14].

The rest of this paper is organized as follows. The mathematical model is introduced in Section II. In Section III 
we describe the procedure used to create the test distribution networks, and in Subsections III-A and III-B test the model on two such systems. We conclude our discussion in Section IV.

\section{MATHEMATICAL MODEL}

\section{A. Nomenclature}

Sets

$\Gamma \quad$ the set of indices for buses;

$\Omega_{0}$ the set of rights of way for existing circuits;

$\Omega_{c} \quad$ the set of rights of way for candidate circuits;

$\Psi \quad$ the set of time periods $\{1,2, \ldots, T\}$

\section{Parameters}

$\alpha_{t k} \quad$ cost of curtailment at time $t$ at bus $k$;

$b_{k} \quad$ cost of installing storage at bus $k$;

$c_{i j} \quad$ cost of installing a circuit on right of way $i j$;

$d_{t k} \quad$ demand at time $t$ at bus $k$;

$\delta^{g} \quad$ ramp rate of generation;

$\delta^{+} \quad$ rate limit of power flow to storage;

$\delta^{-} \quad$ rate limit of power flow from storage;

$e_{k} \quad$ cost of power flow to and from storage at bus $k$;

$\bar{f}_{i j} \quad$ maximum possible power flow on right of way $i j$;

$\bar{g}_{k} \quad$ maximum possible generation at bus $k$;

$\gamma_{i j} \quad$ susceptance of circuits installed on right of way $i j$;

$M_{i j} \quad$ the disjunctive parameter for right of way $i j$

$n_{i j}^{0} \quad$ number of existing circuits on right of way $i j$;

$\bar{n}_{i j} \quad$ maximum number of installable circuits on right of way $i j$;

$\Phi^{+} \quad$ losses of power flow to storage;

$\Phi^{-} \quad$ losses of power flow from storage;

$\Phi^{s} \quad$ losses in storage;

$\bar{x}_{k} \quad$ maximum installable storage capacity at bus $k$

\section{Decision variables}

$\beta_{t k}^{+} \quad$ power flow to storage at bus $k$ at time $t$;

$\beta_{t k}^{-} \quad$ power flow from storage at bus $k$ at time $t$;

$g_{t k} \quad$ generation at time $t$ at bus $k$;

$f_{t i j}^{0} \quad$ power flow for existing circuits at time $t$ on right of way $i j$;

$f_{t i j}^{p} \quad$ power flow for the $p^{\text {th }}$ candidate circuit at time $t$ on right of way $i j$;

$l_{t k} \quad$ level of storage at bus $k$ at time $t$;

$r_{t k} \quad$ demand curtailment at time $t$ at bus $k$;

$\theta_{t k} \quad$ phase angle at time $t$ at bus $k$;

$x_{k} \quad$ storage capacity installed at bus $k$;

$y_{i j}^{p} \quad$ binary variable denoting installation of the $p^{\text {th }}$ candidate circuit on right of way $i j$

\section{B. Model}

The objective of our planning is to minimize the investment costs of installing ESS and new or reinforcing circuits, and to minimize operating costs which are represented by the price of power flow to and from installed ESS facilities and a penalty for curtailed load at demand nodes.

The model facilitates the location and sizing of continuous capacity storage within the network, and the selection of discrete new circuits or reinforcing circuits to be installed on a right of way $i j$. Clearly, the storage will be installed if it is cheaper to do so than to curtail load or install additional circuits.

In order to simulate the operation of the ESS we introduce discrete time $t$. Demand and generation are assumed to be constant for the duration of each time step, however generation is re-dispatchable and demand may vary over time. This allows the storage to function somewhat like a battery; "charging" in periods of lower demand, and "discharging" in periods of higher demand.

The objective is therefore to minimize the function

$$
\begin{aligned}
z=\sum_{(i, j)} c_{i j} y_{i j}^{p}+\sum_{k \in \Gamma} b_{k} x_{k}+\sum_{t \in \Psi} \sum_{k \in \Gamma} \alpha_{t k} r_{t k}+ & \\
& \sum_{t \in \Psi} \sum_{k \in \Gamma} e_{k}\left(\beta_{t k}^{+}+\beta_{t k}^{-}\right)
\end{aligned}
$$

The technical constraints that define the expansion plan are outlined below:

Nodal balance and power flow

$$
\begin{aligned}
\zeta+g_{t k}+r_{t k}-\beta_{t k}^{+}+\beta_{t k}^{-}=d_{t k} \\
\forall t \in \Psi, \forall k \in \Gamma
\end{aligned}
$$

where

$$
\zeta=\sum_{(i, k) \in \Omega_{0}} f_{t i k}^{0}-\sum_{(k, j) \in \Omega_{0}} f_{t k j}^{0}+\sum_{p=1}^{\bar{n}_{i j}} \sum_{(i, k) \in \Omega_{c}} f_{t i k}^{p}-\sum_{p=1}^{\bar{n}_{i j}}
$$

Nodal balance i.e. Kirchhoff's current law is ensured at each time period by constraint (2).

Power flows are modeled using a DC approximation resulting in subsidiary decisions to determine the phase angles at each bus:

$$
\begin{aligned}
& f_{t i j}^{0}-\gamma_{i j} n_{i j}^{0}\left(\theta_{t i}-\theta_{t j}\right)=0 \quad \forall t \in \Psi, \forall(i, j) \in \Omega_{0} \\
& \left|f_{t i j}^{p}-\gamma_{i j}\left(\theta_{t i}-\theta_{t j}\right)\right| \leq M_{i j}\left(1-y_{i j}^{p}\right) \\
& \forall t \in \Psi, \forall(i, j) \in \Omega_{c}, \forall p \in\left\{1 \ldots \bar{n}_{i j}\right\}
\end{aligned}
$$

Kirchhoff's voltage law is implemented for existing circuits by (4), and for candidate circuits by (5). The disjunctive parameter $M_{i j}$ must be sufficiently large so as not to artificially limit power flow on the right of way $i j$.

$$
\begin{aligned}
& \left|f_{t i j}^{0}\right| \leq n_{i j}^{0} \bar{f}_{i j} \quad \forall t \in \Psi, \forall(i, j) \in \Omega_{0} \\
& \left|f_{t i j}^{p}\right| \leq y_{i j}^{p} \bar{f}_{i j} \\
& \quad \forall t \in \Psi, \forall(i, j) \in \Omega_{c}, \forall p \in\left\{1 \ldots \bar{n}_{i j}\right\}
\end{aligned}
$$

Nominal thermal limits are enforced on existing and candidate circuits by (6) and (7) respectively. 
Storage level and charge/discharge limits

$$
\begin{array}{r}
l_{1 k}=\left(1-\Phi^{s}\right) l_{T k}+\left(1-\Phi^{+}\right) \beta_{1 k}^{+}-\left(1+\Phi^{-}\right) \beta_{1 k}^{-} \\
\forall k \in \Gamma \\
l_{t k}=\left(1-\Phi^{s}\right) l_{t-1, k}+\left(1-\Phi^{+}\right) \beta_{t k}^{+}-\left(1+\Phi^{-}\right) \beta_{t k}^{-} \\
\forall k \in \Gamma, \forall t>1 \in \Psi, \forall k \in \Gamma
\end{array}
$$

The set of time periods $\Psi$ is assumed to be cyclic, thus the level of the storage at the last time period is required to be identical to the initial storage state. This is implemented by the "wrap around" constraint (8). For all other time periods the storage level is given by (9).

$$
\begin{aligned}
& \left|\beta_{1 k}^{+}-\beta_{T, k}^{+}\right| \leq \delta^{+} x_{k} \quad \forall k \in \Gamma \\
& \left|\beta_{t k}^{+}-\beta_{t-1, k}^{+}\right| \leq \delta^{+} x_{k} \quad \forall t>1 \in \Psi, \forall k \in \Gamma \\
& \left|\beta_{1 k}^{-}-\beta_{T, k}^{-}\right| \leq \delta^{-} x_{k} \quad \forall k \in \Gamma \\
& \left|\beta_{t k}^{-}-\beta_{t-1, k}^{-}\right| \leq \delta^{-} x_{k} \quad \forall t>1 \in \Psi, \forall k \in \Gamma
\end{aligned}
$$

Constraints (10) and (12) implement the "wrap around" constraints for limits on power flow into and out of storage respectively. For all other time periods these limits are enforced by (11) and (13).

$$
\begin{aligned}
& 0 \leq l_{t k} \leq x_{k} \quad \forall t \in \Psi, \forall k \in \Gamma \\
& 0 \leq x_{k} \leq \bar{x}_{k} \quad \forall k \in \Gamma
\end{aligned}
$$

Constraint (14) ensures the stored energy does not exceed the installed capacity, while constraint (15) establishes bounds on this capacity.

\section{Generation bounds and ramp rate}

$$
\begin{aligned}
& \left|g_{1 k}-g_{T, k}\right| \leq \delta^{g} \bar{g}_{k} \quad \forall k \in \Gamma \\
& \left|g_{t k}-g_{t-1, k}\right| \leq \delta^{g} \bar{g}_{k} \quad \forall t>1 \in \Psi, \forall k \in \Gamma
\end{aligned}
$$

Limits on generation ramp rate are imposed by the "wrap around" constraint (16) and for all other time periods by constraint (17).

$$
0 \leq g_{t k} \leq \bar{g}_{k} \quad \forall t \in \Psi, \forall k \in \Gamma
$$

Generator re-dispatch is permitted within the bounds imposed by (18).

\section{Curtailment bounds}

$$
0 \leq r_{t k} \leq d_{t k} \quad \forall t \in \Psi, \forall k \in \Gamma
$$

Curtailment at any node during a given time period cannot exceed the demand at that node during the same time period.

\section{Symmetry breaking constraints}

$$
y_{i j}^{p} \geq y_{i j}^{p+1} \quad \forall(i, j) \in \Omega_{c}, \forall p \in\left\{1 \ldots \bar{n}_{i j}-1\right\}
$$

The lexicographical constraint (20) eliminates the symmetry introduced by the inclusion of the binary decision variables by mandating the order of installation of parallel circuits be arbitrary.
Other

$$
\begin{aligned}
& y_{i j}^{p} \in\{0,1\} \\
& f_{t i j}^{0}, f_{t i j}^{p}, \beta_{t k}^{+}, \beta_{t k}^{-}, \theta_{t k} \text { unbounded }
\end{aligned}
$$

\section{CASE STUDY}

The Smart Grid, Smart City (SGSC) project was a AUD \$100M Australian government funded project led by Ausgrid that identified and tested a range of smart grid technologies to evaluate the costs and benefits of deploying these technologies in an Australian setting [15]. As part of this project The National Feeder Taxonomy Study identified a small set of 19 feeders representative of network segments typical to the Australian distribution network, as well generic load profiles for residential, commercial, and industrial customers [14].

In this case study we use a selection of these representative feeders to develop test distribution networks and use them to test the expansion planning model discussed in Section II.

Using the SINCAL ${ }^{1}$ models provided in the SGSC information clearing house, we develop the test networks with the following procedure:

1) Represent the entire distribution network as an undirected graph.

2) Identify infeeder and load vertices.

3) Remove edges representing low impedance lines.

4) For all infeeder or load vertices having degree 0 , find the nearest vertex having degree $\geq 0$ by solving the shortest path problem, and assign the infeeder or load to this vertex.

5) Assign loads to all vertices having degree 1 (terminal nodes).

6) Generate the tabulated data for the network.

The technical parameters included in the tabulated data are derived directly from the specification of the electrical system given in the SINCAL model. For simplicity, new lines have been uniformly priced at $\$ 140,000 / \mathrm{km}$. Two new or reinforcing lines may be installed on each right of way. Up to $250 \mathrm{kWh}$ of storage may be installed at any node including transshipment nodes. The cost per MW of long term ( 4 hours) energy storage was estimated to be AUD\$810,451 in 2012 [16, p. 43], and storage in the test systems has been priced accordingly. Load characteristics, including load type (residential, commercial, industrial) and peak load are determined by sampling probability distributions that reflect the description of the representative feeder from the report, as well as the SINCAL model. For example, Representative 11 (Rep11) is described as predominantly residential; the matching parameters used to determine its load characteristics are given in Table I. In this case study, residential loads are assumed to represent a cluster of 40 dwellings within a neighbourhood.

We compare the expansion plan for two seasonal load scenarios: summer and winter. Each scenario comprises 48 periods of 30 minutes. Peak loads are re-scaled according to season and load type using generic load profiles from [14]. Industrial customers utilize the "high load" profile for each season. Fig. 1 shows all load profiles over time.

\footnotetext{
${ }^{1}$ See http://www.simtec.cc/sites_en/sincal.asp
} 
TABLE I. PARAMETERS FOR DETERMINING LOAD CHARACTERISTICS FOR REPRESENTATIVE 11. RESIDENTIAL PEAK LOADS ARE PER DWELLING.

\begin{tabular}{cll}
\hline Variable & Distribution & Parameters \\
\hline Load type & Multinomial & $n=1$ \\
& & $\mathrm{P}($ residential $)=0.85$ \\
& & $\mathrm{P}($ commercial $)=0.15$ \\
& & $\mathrm{P}($ industrial $)=0$ \\
Residential peak load & Normal & $\sim \mathrm{N}(9.4 \mathrm{~kW}, 0.5 \mathrm{~kW})$ \\
Commercial peak load & Normal & $\sim \mathrm{N}(150 \mathrm{~kW}, 10 \mathrm{~kW})$ \\
\hline
\end{tabular}

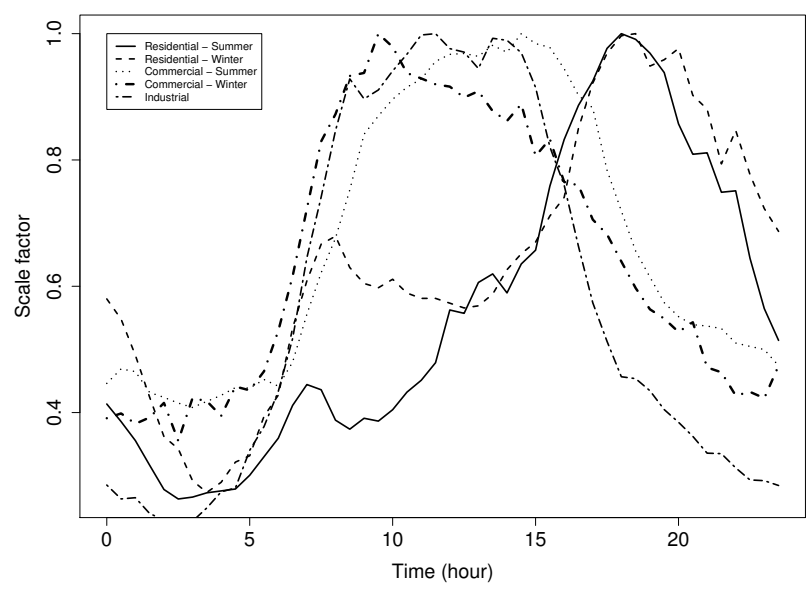

Fig. 1. Seasonal load profiles from [14].

\section{A. Representative 11}

Rep11 is an $11 \mathrm{kV}$ medium density network of predominately residential customers. For the purposes of this case study, it has 27 buses with an infeeder located at bus 1 . There are 14 residential load clusters, and two commercial loads. Peak demand in the network is $4.61 \mathrm{MW}$. The initial network topology of the Rep11 test network is shown in Fig. 2.

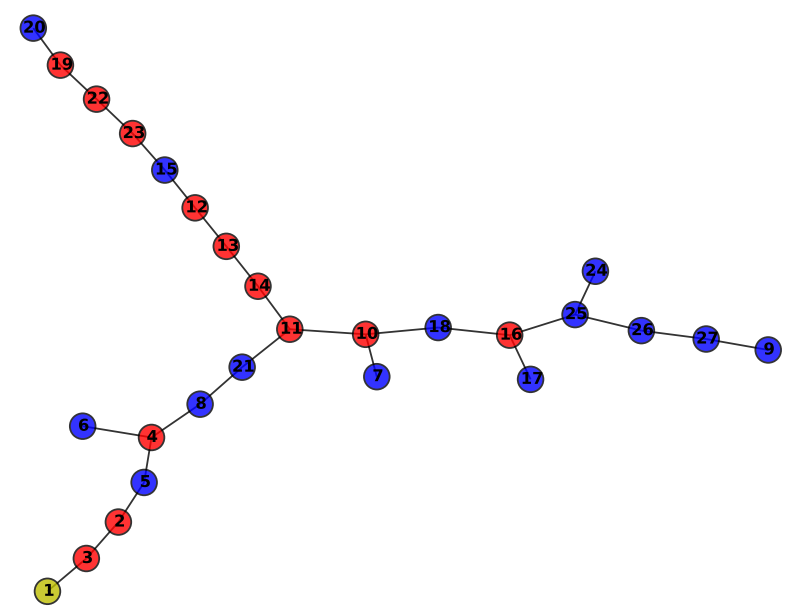

Fig. 2. Topology of representative 11. The infeeder is shown in yellow, transshipment nodes in red, and loads in blue.

Parameters to the model governing the operation of generators (ramp rate) and ESS (charge/discharge rate, losses, etc.) are given in Table II. The model was solved using IBM ILOG CPLEX 12.6.1 on an Apple MacBook Air with 8GB of RAM.

TABLE II. PARAMETER VALUES GOVERNING THE OPERATION OF GENERATORS AND ESS.

\begin{tabular}{cccc}
\hline Parameter(s) & Description & Value & Units \\
\hline$\delta^{g}$ & generation ramp rate & 0.25 & - \\
$\delta^{+}, \delta^{-}$ & charge/discharge rate limit & 0.30 & - \\
$e_{k}$ & cost of power flow to storage & 0.0001 & AUD\$ \\
$\Phi^{+}, \Phi^{-}$ & rate of power flow losses to/from storage & 0.05 & - \\
$\Phi^{s}$ & rate of losses in storage & 0.0001 & - \\
$\alpha^{t k}$ & cost of curtailment & $20,000,000$ & AUD\$/MWh \\
\hline
\end{tabular}

Results of the optimization are tabulated in Table III. The cost of the optimal expansion plan for both summer and winter is $\$ 166,141$ with new circuits installed on rights of way $2-5$, $4-5,4-8$, and 8-21. As the cost of installing the new lines is significantly less than the cost of storage, ESS are omitted from the plan. If the installation of lines is disallowed, the cost of the optimal expansion plan that satisfies summer demand is $\$ 4.8 \mathrm{M}$, and $5.93 \mathrm{MWh}$ of storage is required. For winter the total cost rises to $\$ 14.2 \mathrm{M}$, although a similar amount of storage is installed (6.00MWh). The large cost discrepancy can be attributed to the high cost of the load curtailment necessary to produce a feasible plan for winter demand.

To discover the maximum price at which ESS is installed, the model was run repeatedly and the cost of storage reduced by $\$ 5000$ each iteration until ESS were included in the plan. In the case of the summer demand profiles, storage will not be installed until the cost falls to $\$ 180,000 / \mathrm{MWh}$. For winter the maximum price of storage is slightly higher at $\$ 200,000 / \mathrm{MWh}$. The operation of the ESS over time for this expansion plan is shown in Fig. 3.

TABLE III. TABULATED RESULTS FOR REP11.

\begin{tabular}{|c|c|c|c|c|c|c|}
\hline Season & Lines & $\begin{array}{l}\text { Storage Cost } \\
\text { (AUD\$/MWh) }\end{array}$ & $\begin{array}{c}\text { Total Cost } \\
\text { (AUD\$) }\end{array}$ & Circuits & $\begin{array}{c}\text { Total Storage } \\
(\mathrm{MWh})\end{array}$ & $\begin{array}{c}\text { Curtailment } \\
\text { (MWh) }\end{array}$ \\
\hline Summer & $\mathrm{y}$ & 810,000 & 166,141 & $\begin{array}{l}2-5(1) \\
4-5(1) \\
4-8(1) \\
8-21(1)\end{array}$ & 0 & 0 \\
\hline Summer & $\mathrm{y}$ & 180,000 & 163,058 & $\begin{array}{l}2-5(1) \\
4-5(1) \\
4-8(1)\end{array}$ & 0.39 & 0 \\
\hline Summer & $\mathrm{n}$ & 810,000 & $4,805,357$ & - & 5.93 & 0 \\
\hline Winter & $\mathrm{y}$ & 810,000 & 166,141 & $\begin{array}{l}2-5(1) \\
4-5(1) \\
4-8(1) \\
8-21(1)\end{array}$ & 0 & 0 \\
\hline Winter & $\mathrm{y}$ & 200,000 & 165,844 & $\begin{array}{l}2-5(1) \\
4-5(1) \\
4-8(1)\end{array}$ & 0.37 & 0 \\
\hline Winter & $\mathrm{n}$ & 810,000 & $14,187,744$ & - & 6.00 & 0.47 \\
\hline
\end{tabular}

\section{B. Representative 10}

Representative 10 (Rep10) is an $11 \mathrm{kV}$ medium density network. Demand is primarily residential, however there are some commercial customers. For this case study we also add two industrial loads of $157 \mathrm{~kW}$ and $302 \mathrm{~kW}$ to bus 3 and bus 6 respectively. The network has 78 buses with an infeeder located at bus 1 . In addition to the two industrial loads, there are 16 residential load clusters, and four commercial loads. Peak demand in the network is 7MW. The initial network topology of the Rep10 test network is shown in Fig. 4. 


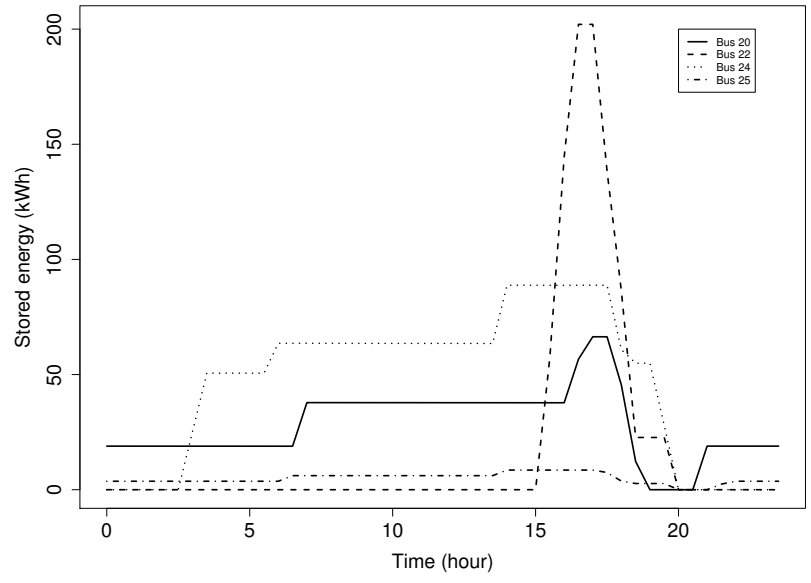

Fig. 3. Operation of ESS during winter (storage cost $\$ 200,000$ ). The effect of the "wrap around" constraints is quite obvious.

Parameters used to determine the load characteristics for Rep10 are given in Table IV. Other parameters to the model and computing environment remain unchanged from those used in Subsection III-A.

TABLE IV. PARAMETERS FOR DETERMINING LOAD CHARACTERISTICS FOR REPRESENTATIVE 10. RESIDENTIAL PEAK LOADS ARE PER DWELLING.

\begin{tabular}{ccl}
\hline Variable & Distribution & Parameters \\
\hline Load type & Multinomial & $n=1$ \\
& & $\mathrm{P}($ residential $)=0.75$ \\
& & $\mathrm{P}($ commercial $)=0.20$ \\
& & $\mathrm{P}($ industrial $)=0.05$ \\
Residential peak load & Normal & $\sim \mathrm{N}(9.4 \mathrm{~kW}, 0.5 \mathrm{~kW})$ \\
Commercial peak load & Normal & $\sim \mathrm{N}(150 \mathrm{~kW}, 10 \mathrm{~kW})$ \\
Industrial peak load & Normal & $\sim \mathrm{N}(250 \mathrm{~kW}, 50 \mathrm{~kW})$ \\
\hline
\end{tabular}

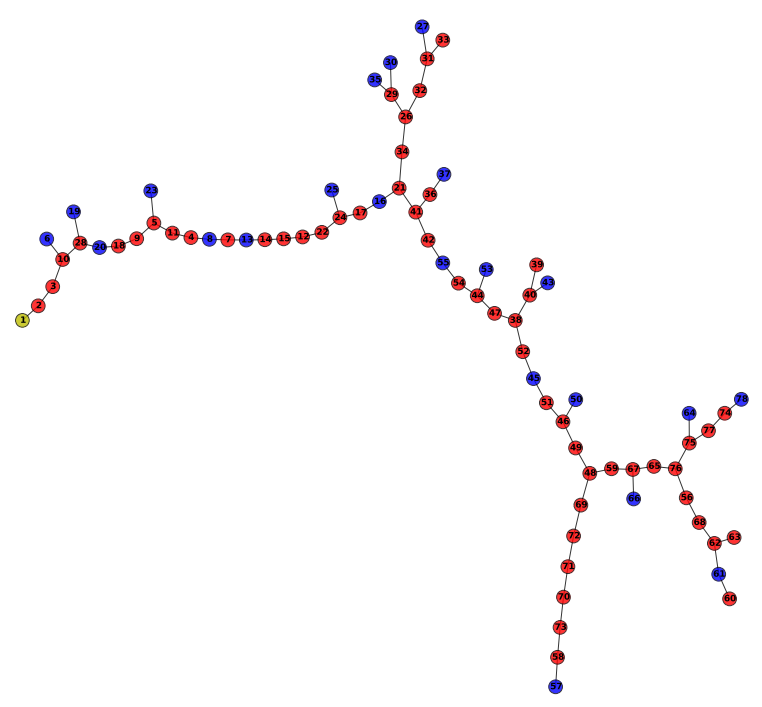

Fig. 4. Topology of representative 10. The infeeder is shown in yellow, transshipment nodes in red, and loads in blue.

Results of the optimization are tabulated in Table V. The cost of the optimal expansion plan for the summer season is $\$ 238,800$ with one new circuit installed on rights of way $2-3$, 3-10, 5-9, 5-11, 9-18, 10-28, 12-15, 12-22, 16-17, 16-21, 17$24,18-20,20-28,22-24$, and two new circuits installed on right of way 1-2. As with Rep11, storage is omitted from the plan as it more economical to install new lines. If the installation of lines is disallowed, 6.2MWh of storage is installed however $20.18 \mathrm{MWh}$ of demand must be curtailed resulting in the cost of the expansion plan exceeding $\$ 408 \mathrm{M}$. The maximum cost of storage that will defer circuit upgrades is $\$ 410,000 / \mathrm{MWh}$ (to the nearest $\$ 5000$ ). In this case an ESS with a capacity of $14 \mathrm{kWh}$ is installed at bus 48 in lieu of the installation of a circuit on right of way 16-21.

For the winter season the cost of the optimal expansion plan is $\$ 232,962$. Storage is again omitted, however two new circuits are installed on rights of way 1-2 and 12-15, and one new circuit is required on rights of way $2-3,3-10,5-9,5-$ $11,9-18,10-28,12-22,16-17,17-24,18-20,20-28$, and $22-$ 24. Disallowing the installation of lines results in $30.36 \mathrm{MWh}$ of load curtailment at a total cost of over $\$ 620 \mathrm{M}$. A paltry $3.05 \mathrm{MWh}$ of storage is installed. ESS may be included in the expansion plan if the cost of storage falls to $\$ 170,000 / \mathrm{MWh}$ or below.

TABLE V. TABUlated Results FOR REP10.

\begin{tabular}{|c|c|c|c|c|c|c|}
\hline Season & Lines & $\begin{array}{l}\text { Storage Cost } \\
\text { (AUD\$/MWh) }\end{array}$ & $\begin{array}{l}\text { Total Cost } \\
\text { (AUD\$) }\end{array}$ & Circuits & $\begin{array}{c}\text { Total Storage } \\
(\mathrm{MWh})\end{array}$ & $\begin{array}{c}\text { Curtailment } \\
\text { (MWh) }\end{array}$ \\
\hline Summer & $\mathrm{y}$ & 810,000 & 238,800 & $\begin{array}{l}1-2(2) \\
2-3(1) \\
3-10(1) \\
5-9(1) \\
5-11(1) \\
9-18(1) \\
10-28(1) \\
12-15(2) \\
12-22(1) \\
16-17(1) \\
16-21(1) \\
17-24(1) \\
18-20(1) \\
20-28(1) \\
22-24(1)\end{array}$ & 0 & 0 \\
\hline Summer & $\mathrm{y}$ & 410,000 & 238,543 & $\begin{array}{l}\text { As above } \\
\text { except } \\
16-21 \text { (1) } \\
\text { is omitted. }\end{array}$ & 0.014 & 0 \\
\hline Summer & $\mathrm{n}$ & 810,000 & $408,613,264$ & - & 6.20 & 20.18 \\
\hline Winter & y & 810,000 & 232,962 & $\begin{array}{l}1-2(2) \\
2-3(1) \\
3-10(1) \\
5-9(1) \\
5-11(1) \\
9-18(1) \\
10-28(1) \\
12-15(2) \\
12-22(1) \\
16-17(1) \\
17-24(1) \\
18-20(1) \\
20-28(1) \\
22-24(1)\end{array}$ & 0 & 0 \\
\hline Winter & y & 170,000 & 232,129 & $\begin{array}{l}\text { As above } \\
\text { except } \\
1-2(1)\end{array}$ & 0.19 & 0 \\
\hline Winter & $\mathrm{n}$ & 810,000 & $620,098,411$ & - & 3.05 & 30.36 \\
\hline
\end{tabular}

\section{CONCLUSION}

In this paper we have developed an improved mixed integer programming (MIP) model for electricity network expansion planning including the location and sizing of energy storage systems, and have shown how representative feeder taxonomies identified as part of the Smart Grid, Smart City project's National Feeder Taxonomy Study may be modified to produce new distribution expansion planning test systems. 
The model has been used to produce optimal expansion plans that satisfy two seasonal load scenarios, summer and winter.

Our results show ESS unlikely to be included in the expansion plan where circuit installation is of comparatively low cost as is the case today. To be included in the optimal expansion plan the cost of storage must decrease by at least $50 \%$, depending on both test network and the load scenario under which the storage is operated.

\section{ACKNOWLEDGMENT}

The second author is supported by the Australian Research Council under the Discovery Projects funding scheme (project DP140104246).

\section{REFERENCES}

[1] S. Khator and L. Leung, "Power distribution planning: a review of models and issues," IEEE Transactions on Power Systems, vol. 12, no. 3 , pp. 1151-1159, 1997, r.

[2] R. Romero, A. Monticelli, A. Garcia, and S. Haffner, "Test systems and mathematical models for transmission network expansion planning," Generation, Transmission and Distribution, IEEE Proceedings-, vol. 149, no. 1, pp. 27-36, 2002.

[3] L. Garver, "Transmission network estimation using linear programming," IEEE Transactions on Power Apparatus and Systems, vol. PAS89, no. 7, pp. 1688-1697, 1970.

[4] Z. Hu, F. Zhang, and B. Li, "Transmission expansion planning considering the deployment of energy storage systems," in 2012 IEEE Power and Energy Society General Meeting, 2012, pp. 1-6.

[5] F. Zhang, Z. Hu, and Y. Song, "Mixed-integer linear model for transmission expansion planning with line losses and energy storage systems,' Generation, Transmission Distribution, IET, vol. 7, no. 8, pp. 919-928, Aug. 2013.

[6] C. T. M. Clack, Y. Xie, and A. E. MacDonald, "Linear programming techniques for developing an optimal electrical system including highvoltage direct-current transmission and storage," International Journal of Electrical Power \& Energy Systems, vol. 68, pp. 103-114, Jun. 2015, r.
[7] M. Sedghi, M. Aliakbar-Golkar, and M.-R. Haghifam, "Distribution network expansion considering distributed generation and storage units using modified PSO algorithm," International Journal of Electrical Power \& Energy Systems, vol. 52, pp. 221-230, Nov. 2013.

[8] A. F. Crossland, D. Jones, and N. S. Wade, "Planning the location and rating of distributed energy storage in LV networks using a genetic algorithm with simulated annealing," International Journal of Electrical Power \& Energy Systems, vol. 59, pp. 103-110, Jul. 2014, r.

[9] R. Jabr, I. Dzafic, and B. Pal, "Robust Optimization of Storage Investment on Transmission Networks," IEEE Transactions on Power Systems, vol. 30, no. 1 , pp. 531-539, Jan. 2015.

[10] J. Wood, "Integrating renewables into the grid: Applying UltraBattery \#x00ae; Technology in MW scale energy storage solutions for continuous variability management," in 2012 IEEE International Conference on Power System Technology (POWERCON), Oct. 2012, pp. 1-4.

[11] A. T. Ernst and G. Singh, "Taming Wind Energy with Battery Storage," in Operations Research Proceedings 2007, ser. Operations Research Proceedings, D. J. Kalcsics and P. D. S. Nickel, Eds. Springer Berlin Heidelberg, 2008, no. 2007, pp. 199-204.

[12] P. Zhao, J. Wang, and Y. Dai, "Capacity allocation of a hybrid energy storage system for power system peak shaving at high wind power penetration level," Renewable Energy, vol. 75, pp. 541-549, Mar. 2015, r.

[13] C. MacRae, M. Ozlen, and A. Ernst, "Transmission expansion planning considering energy storage," in Power, Electronics and Computing (ROPEC), 2014 IEEE International Autumn Meeting on, Nov 2014.

[14] A. Berry, T. Moore, J. Ward, S. Lindsay, and K. Proctor, "National Feeder Taxonomy - Describing a Representative Feeder Set for Australian Electricity Distribution Networks." CSIRO, Australia, Jun. 2013.

[15] "Smart Grid, Smart City: Shaping Australia's Energy Future National Cost Benefit Assessment," Jul. 2014. [Online]. Available: https://ich.smartgridsmartcity.com.au/Home/SGSC-Report/FinalReport/Final-Report-Downloads/ARUP_SGSC-Shaping-AustraliaEnergy-Future-National.aspx

[16] "Energy storage in australia. commercial opportunities, barriers and policy options," Marchment Hill Consulting, Tech. Rep. Version 1, Nov. 2012. 